\title{
B.Н. Бобков
}

Институт социально-экономических проблем народонаселения Федерального научно-исследовательского социологического центра РАН, Москва

\section{Е.В. Одинцова}

Институт социально-экономических проблем народонаселения Федерального научно-исследовательского социологического центра РАН, Москва

\section{Социальное неравенство в России ${ }^{1}$}

Аннотация. В статье показано, что әкономические характеристики неравенства являются частью более широкого явления - социального неравенства. Рассмотрены основные области его проявления: по денежным доходам и богатству; текущему потреблению благ; доступу к жилищу и инфраструктуре социальной сферы; а также - в пространственном аспекте; уровне и качестве жизни городского и сельского населения; отраслевом разрезе; возрастных демографических группах; применении цифровых технологий. Проведено оценивание неравенства и аргументированы его высокие размеры, что выражается в нахождении России в группе стран с наиболее высоким уровнем неравенства по доходам и богатству; в десятикратном разрыве средних потребительских расходов у $10 \%$ наиболее и наименее доходных групп домохозяйств; в более чем десятикратной дифференциации численности граждан с жилищной бедностью и высокообеспеченных жильем; в недоступности для половины студентов колледжей и вузов обучения за счет бюджетных ассигнований; в разрыве ожидаемой продолжительности жизни при рождении в субъектах РФ с наибольшим и наименьшим значением показателя, составляющим 16 лет; в 3-5 раз более высоком уровне безработицы среди молодежи по сравнению с другими группами экономически активного населения и др. Поставлен вопрос о необходимости разработки национальной программы повышения реальных денежных доходов населения, снижения бедности и неравенства.

Ключевые слова: экономическое неравенство, сочиальное неравенство, высокое неравенство, бедность, реальные денежные доходь, программа снижения бедности и неравенства.

Классификация JEL: E21, E24, E64, I3, J21.

DOI: $10.31737 / 2221-2264-2020-47-3-8$

\section{1. Введение}

Высокое неравенство выражается в сосредоточении общего объема денежных доходов, а в более широком контексте, национального богатства (состояний), у незначительной части граждан страны, в то время как другая их, гораздо более представительная, часть лишена возможностей такого жизненного уровня, включая пищу, одежду, жилище, медицинское обслуживание и социальное обеспечение, а также образование, которые необходимы для поддержания ее здоровья и благосостояния (МOT, 1957-1990, с. 1321-1329).

Оценки проблемы неравенства в нашей стране, данные Президентом Российской Федерации В.В. Путиным, о вызывающе великой дифференциации доходов, о воспринимаемом как несправедливость и служащим источником социальной напряженности избыточном разрыве в доходах (Путин, 2012), не теряют своей актуальности.
По этим вопросам в мире ведется широкая дискуссия (Бузгалин, Трауб-Мерц, Воейков, 2014; Пикетти, 2016; Рубинштейн, 2018; Dalton, 1920; Milanovic, 2014; Solt, 2019; и др.). Авторами статьи приводится дополнительная аргументация избыточности неравенства в России (Шевяков, Кирута, 2002). В статье экономическое неравенство рассматривается как часть социального неравенства (Российское общество..., 2015-2017; Средние классы..., 2019; и др.).

\section{2. Сферы проявления социального неравенства и его размеры}

1. Неравенство по доходам и богатству. По размерам коэффициента Джини (КДж) по денежным доходам и ВВП по паритету покупательной способности (ППС) Россия $(0,412$; 24072 долл. в 2016 г.) находится в группе стран с наиболее высоким уровнем әкономического

\footnotetext{
${ }^{1}$ Исследование выполнено в рамках государственного задания по теме: «Компоненты, социальные стандарты и индикаторы уровня и качества жизни населения в современной России: качественная идентификация и количественное оценивание в условиях социально-экономического неравенства» (№ 0137-2019-0032).
} 
неравенства (Аргентина (0,412; 20843 долл. в 2017 г.), Китай $(0,386 ; 14455$ долл. в 2015 г.), Турция $(0,404 ; 25626$ долл. в 2015 г.)), в то время как размер душевого ВВП по ППС стран этой группы существенно ниже по сравнению с группой стран со значительно более низким КДж (по данным 2017 г.): Германия $(0,289$; 52055 долл.), Италия (0,334; 41200 долл.), Канада $(0,310 ; 46723 \text { долл. })^{2}$. В США $(0,390$; 59928 долл.) при сопоставимом с Россией уровне КДж размер душевого дохода примерно в 2,5 раза выше. КДж, определенный по распределению богатства, является в нашей стране наиболее высоким среди сравниваемых стран (2019 г.): Германия $(0,816)$, Китай $(0,702)$, Россия (0,879), США $(0,852)$, Япония $(0,626)$ и др. в расчете на взрослого гражданина, а по размерам богатства наша страна значительно отстает от них: Германия (216 654 долл.), Китай (58 544 долл.), Россия (27 381 долл.), США (432 365 долл.), Япония (238 104 долл.) и др. (Global wealth report, 2019).

\section{2. Неравенство в текущем потреблении благ.}

Потребительские расходы в среднем на члена домохозяйства в десятой, с наиболее высокими, и в первой, с наиболее низкими, располагаемыми ресурсами, группах в 2018 г. различались в 9,8 раза. На покупку непродовольственных товаров - в 19 раз, на оплату услуг - почти в 11 раз. Наибольшие разрывы (более 60 раз) по потреблению услуг отмечаются по услугам учреждений культуры, медицинским и прочим услугам ${ }^{3}$.

3. Неравенство в доступе $к$ жилиу, инфраструктуре сочиальной сферы ${ }^{4}$. Около $40 \%$ населения России не имеет жилищных условий, которые удовлетворяют минимальным нормативным требованиям к площади жилья и/ или его благоустроенности ${ }^{5}$; в жилище у значительной доли домохозяйств отсутствует центральное горячее водоснабжение (у более $40 \%$ ), центральное отопление (у 30\%), коммунальная канализация (у около 27\%). Для консультации (обследования) у врача-специалиста 27,3\% пациентов приходится выезжать в другой населенный пункт в регионе проживания или вообще в другой регион. Из-за финансовых ограничений не имеют возможности посещать дополнительные платные занятия для развития детей до 15 лет члены 31,2\% домохозяйств. Примерно для половины студентов колледжей и вузов недоступным является обучение за счет бюджетных ассигнований (Индикаторы образования..., 2018).

4. Пространственное неравенство 6 .

Результаты анализа показывают высокие разрывы по абсолютной монетарной бедности 6,2 раза (Республика Тыва / Ямало-Ненецкий АО) при ее среднероссийском значении $12,3 \%$ (2019 г.); покупательной способности региональных среднедушевых денежных доходов - 3,3 раза (Ямало-Ненецкий $\mathrm{AO} /$

2 The World Bank, International Comparison Program database (https://data.worldbank.org/indicator/NY.GDP.PCAP. PP.CD?end=2018\&start=2017\&view=chart); OECD Data, Income inequality (https://data.oecd.org/inequality/incomeinequality.htm).

${ }^{3}$ На основе данных Росстата: «Доходы, расходы и потребление домашних хозяйств в 2018 году (по итогам выборочного обследования бюджетов домашних хозяйств)» (https://gks.ru/bgd/regl/bl8_102/Main.htm).

${ }^{4}$ На основе данных Росстата «Комплексное наблюдение условий жизни населения - 2018 r.» (https://gks.ru/free_doc/ new_site/KOUZ18/index.html); «Условия проживания домашних хозяйств, благоустройство жилья, проживание в домах, оборудованных различными видами благоустройства» (https:/www.gks.ru/folder/13397); «Выборочное наблюдение качества и доступности услуг в сферах образования, здравоохранения и социального обслуживания, содействия занятости населения - 2019 г.» (https://gks.ru/free_doc/new_site/GKS_KDU_2019/index.html).

${ }^{5}$ Оценка сделана авторами на основе данных 27 волны РМЭЗ «Российский мониторинг экономического положения и здоровья населения НИУ ВШЭ (RLMS HSE)», проводимый НИУ ВЩЭ и ООО «Демоскоп» при участии Центра народонаселения Университета Северной Каролины в Чапел Хилле и Института социологии Федерального научноисследовательского социологического центра PAH (сайты обследования RLMS HSE: http://www.cpc.unc.edu/ projects/rlms и http://www.hse.ru/rlms).

${ }^{6}$ На основе данных Росстата «Численность населения с денежными доходами ниже величины прожиточного минимума в целом по России и по субъектам Российской Федерации» (https://www.gks.ru/folder/13723); «Коэффициент фондов» (https://fedstat.ru/indicator/31170), «Ожидаемая продолжительность жизни при рождении за 2019 год» (https://gks.ru/folder/12781), «Среднедушевые денежные доходы населения по субъектам Российской Федерации» (https://www.gks.ru/folder/13397), «Величина прожиточного минимума в целом по России и по субъектам Российской Федерации» (https://www.gks.ru/folder/13723) и Аналитического центра при Правительстве РФ (Доклад..., 2018). 
Республика Тыва) (2019 г.); децильному коэффициенту фондов - 2,2 раза (Ямало-Ненецкий АО / Республика Ингушетия) (2019 г.); региональному душевому ВВП по ППС - 34,8 раза (2016 г.) (Ненецкий АО / Чеченская Республика). По обобщающим показателям неравенство составляло по ожидаемой продолжительности жизни при рождении, $-15,8$ лет (Республика Ингушетия / Республика Тыва) (2019 г.), а по индексу человеческого развития (2016 г.) - 0,166 (г. Москва / Республика Тыва).

5. Неравенство городского и сельского населения ${ }^{7}$. Проявляется в более чем в три раза высоком уровне абсолютной и относительной монетарной бедности у сельских жителей. В городах около $3 \%$ домохозяйств проживают в жилище, не снабженном центральным водопроводом, тогда как на селе их доля почти в 10 раз больше. Центральным горячим водоснабжением жилище не обеспечено в городах у $28 \%$, на селе - у более $80 \%$ домохозяйств. Центральное отопление отсутствует в жилище в городах у около $15 \%$, а на селе у $77 \%$ домохозяйств. В жилище не имеют коммунальной канализации в городах 12\%, на селе $-71 \%$ домохозяйств. Отсутствие нужного специалиста для сельских жителей является более распространенной причиной неполучения амбулаторно-поликлинической помощи $(48,6 \%$ от числа обратившихся и не получивших помощь), чем для горожан $(39,8 \%)$. Селянам значительно чаще приходится выезжать для консультаций и прохождения медицинского обследования в другой населенный пункт своего региона (более $50 \%$ ) или в региональный центр (более $22 \%$ ).

\section{6. Отраслевое неравенство. Разрыв} в уровне среднемесячной номинальной начисленной заработной платы (СЗП) по видам экономической деятельности (ВЭД) составлял в 2018 г. 3,5 раза. В ряде ВЭД - «Добыча полезных ископаемых» и «Деятельность финансовая и страховая» - СЗП в 2018 г. была примерно в два раза выше средней по России (43 724 руб.) при относительно незначительном числе работников, получающих такую заработную плату. Наоборот, в большинстве таких ВЭД, как «Образование» и «Деятельность в области здравоохранения и социальных услуг» и др., СЗП была ниже среднероссийского уровня, а численность работников с низкой СЗП была на порядок больше . $^{8}$

7. Возрастное неравенство ${ }^{9}$. Проявляется в гораздо более высоком уровне безработицы среди молодежи (15-29 лет), которое более чем в пять (15-19 лет) и три раза (20-24 года) выше среднего уровня для ее отдельных возрастных групп. С началом пенсионной реформы заметно растет уровень безработицы среди рабочей силы в предпенсионном возрасте (5560 лет) (За давностью лет..., 2019). Результаты опросов свидетельствуют о многочисленных фактах возрастной дискриминации, выражающейся в отказе в приеме молодежи и лиц предпенсионного возраста на работу.

8. Цифровое неравенство ${ }^{10}$. Около $28 \%$ домохозяйств не имеют персонального компьютера, около 31\% - доступа к сети Интернет с домашнего компьютера, около 27\% - широкополосного доступа к сети Интернет. Степень дифференциации уровня использования

\footnotetext{
7 На основе данных Росстата «Выборочное наблюдение доходов населения и участия в социальных программах 2018 г.» (https://gks.ru/free_doc/new_site/vndn-2018/index.html); «Комплексное наблюдение условий жизни населения - 2018 г.» (https://gks.ru/free_doc/new_site/KOUZ18/index.html); «Условия проживания домашних хозяйств, благоустройство жилья, проживание в домах, оборудованных различными видами благоустройства» (https://www. gks.ru/folder/13397), «Выборочное наблюдение качества и доступности услуг в сферах образования, здравоохранения и социального обслуживания, содействия занятости населения - 2019 г.» (https://gks.ru/free_doc/new_site/ GKS_KDU_2019/index.html).

${ }^{8}$ На основе данных Росстата «Среднемесячная номинальная начисленная заработная плата работников организаций по видам экономической деятельности» (https://www.gks.ru/labour_costs); «Величина прожиточного минимума в целом по России и по субъектам Российской Федерации» (https://www.gks.ru/folder/13723); «Oбследование рабочей силы - 2018 г.» (https://www.gks.ru/folder/11110/document/13265).

${ }^{9}$ На основе данных Росстата «Обследование рабочей силы - 2018 г.» (https://www.gks.ru/folder/11110/document /13265) и (Работа и возраст, 2018).

10 На основе данных Росстата «Мониторинг развития информационного общества в Российской Федерации» (https://www.gks.ru/folder/14478); «Влияние цифровых технологий на качество жизни» (https://issek.hse.ru/
} news/305944582.html). 
Интернета является высокой $(88,9 \%)$, в том числе за счет существенного разрыва в навыках населения. Значительно меньшая его часть использует Интернет в целях получения занятости и повышения уровня образования (от $39,7 \%$ до 2,1\% пользователей). Для других целей (участие в социальных сетях, телефонные звонки или видеоразговоры и т.п.) Интернет используют от $24,9 \%$ до $77,8 \%$ пользователей (Информационное общество..., 2019). Будет возрастать неравенство в сфере интеллектуальных продуктов и технологий между их покупателями, создателями и теми, кто не могут себе позволить их приобрести (Футуролог..., 2019).

$$
* * *
$$

Необходимость разработки программы снижения бедности и неравенства существовала и ранее (Бобков, Одинцова, 2019). В связи с последствиями коронавирусной инфекции для населения и экономики чувствительность общества к этим проблемам обострилась. Разработка национальной Программы повышения реальных доходов населения, снижения бедности и неравенства становится все более актуальной.

\section{ЛИТЕРАТУРA / REFERENCES}

Бобков В.Н., Одинцова Е.В. (2019). Стране необходима национальная программа повышения реальных доходов населения и снижения бедности // Ажmyальные проблемь сочиально-экономиче ского развития России. № 1. С. 99-114.

[Bobkov V.N., Odintsova E.V. (2019). The country needs a national program to increase real incomes and reduce poverty. Actual Problems of Social-Economic Development of Russia, 1, 99-114 (in Russian).]

Бузгалин А., Трауб-Мерц Р., Воейков М. (ред.) (2014). Неравенство доходов и экономический рост: стратегии выхода из кризиса. М.: Культурная революция. [Buzgalin A., Traub-Merc R., Voejkova M. (eds.) (2014). Income inequality and economic growth: Strategies for overcoming the crisis. Moscow: Kulturnaja revoljucija (in Russian).]

Доклад о человеческом развитии в Россий- ской Федерации (2018). С.Н. Бобылев, Л.М. Григорьев (ред.). М.: Аналитический центр при Правительстве Российской Федерации. [Human develop ment report for the Russian Federation (2018). S.N. Bobylev, L.M. Grigoriev (eds.). Moscow: Analytical Center for the Government of the Russian Federation (in Russian).]

За давностью лет: в РФ не заводят дела за увольнение предпенсионеров // Известия. Режим доступа: https://iz.ru/932926/ anna-ivushkina-sergei-izotov/za-davnostiulet-v-rf-ne-zavodiat-dela-za-uvolnenie-predpensionerov [For the prescription of years: In the Russian Federation do not start cases for the dismissal of pre-pensioners. Izvestia. Available at: https://iz.ru/932926/annaivushkina-sergei-izotov/za-davnostiu-let-vrf-ne-zavodiat-dela-za-uvolnenie-predpensionerov (in Russian).]

Индикаторы образования: 2018. Статистический сборник (2018). М.: НИУ ВШЭ. [Indi cators of education: 2018. Statistical collection (2018). Moscow: NRU HSE (in Russian).]

Информационное общество в Российской Федерации: 2019. Статистический сборник (2019). М.: НИУ ВШЭ. [Information society in the Russian Federation: 2019. Statistical collection (2019). Moscow: NRU HSE (in Russian).]

MOT: Конвенции и рекомендации, принятые Международной конфедерацией труда (1957-1990). Международное бюро труда. Т. 2 [ILO: conventions and recommendations adopted by the International Labour Confederation (1957-1990). International Labour Organization. Vol. 2 (in Russian).]

Пикетти Т. (2016). Капитал в XXI веке. М.: АД Маргинем Пресс. [Piketty T. (2016). Capital in the 21st Century. Moscow: AD Marginem Press (in Russian).]

Путин В. (2012). Строительство справедливости. Социальная политика для России. Режим доступа: https://www. kp.ru/daily/25833/2807793/ [Putin V. (2012). Building justice. Social policy for Russia. Available at: https://www.kp.ru/ daily/25833/2807793 / (in Russian).] 
Работа и возраст (2018). М.: Фонд общественное мнение. Режим доступа: https:// fom.ru/Ekonomika/14081 [Work and age (2018). Moscow: Fond obshchestvennoe mnenie. Available at: https://fom.ru/ Ekonomika/14081 (in Russian).]

Российское общество и вызовы времени (2015-2017). Книги 1-5. М.К. Горшков (ред.). М.: Весь мир. [Russian society and challenges of the time (2015-2017). Books 1-5. M.K. Gorshkov (ed.). Moscow: Ves' mir (in Russian).]

Рубинштейн А.Я. (2018). Теория опекаемых благ: учебник. СПб.: Алетейя [Rubinstein A.Ya. (2018). Theory of patronized goods: Textbook. Saint-Petersburg: Aleteia (in Russian).]

Средние классы в капиталистической России (2019). В.Н. Бобков (гл. научн. ред.). 2-е изд. М.: КНОРУС. [Middle classes in the capitalist Russia (2019). V.N. Bobkov (chief sci. ed.). $2^{\text {nd }}$ ed. Moscow: KNORUS (in Russian).]

Футуролог: Мир, к которому мы привыкли, скоро перестанет существовать (2019). Режим доступа: https://incrussia.ru/ news / mir-k-kotoromu-my-privykli / [ Futur- ologist: The world we are used to will soon cease to exist. Available at: https://incrussia.ru/ news / mir-k-kotoromu-my-privykli/(in Russian).]

Шевяков А.Ю., Кирута А.Я. (2002). Измерение экономического неравенства. М.: Лето. [Shevjakov A.Yu., Kiruta A.Ya. (2002). The measurement of economic inequality. Moscow: Leto (in Russian).]

Dalton H. (1920). The Measurement of the Inequality of Incomes. The Economic Journal, 30, 119, 348-361.

Global wealth report 2019 (2019). Credit Suisse Research Institute. Available at: https:// www.credit-suisse.com/about-us / en / reports-research/global-wealth-report.html

Milanovic B. (2014). Global income inequality in numbers: In history and now. An overview of the reports to the XV Apr. international scientific conf. on development of economy and society. Moscow, April 1-4, 2014. Moscow: Publishing House of the Higher School of Economics.

Solt F. (2019). Measuring income inequality across countries and over time: The standardized world income inequality database. SocArXiv, July, 1-23.

Поступила в редакиию 19.04.2020

Received 19.04.2020

\section{V.N. Bobkov}

Institute of Socioeconomic Studies of Population, Federal Center of Theoretical and Applied Sociology of the Russian Academy of Sciences, Moscow

\section{E.V. Odintsova}

Institute of Socioeconomic Studies of Population, Federal Center of Theoretical and Applied Sociology of the Russian Academy of Sciences, Moscow

\section{Social Inequality in Russia ${ }^{11}$}

Abstract. The article shows that the economic characteristics of inequality are part of a broader phenomenon - social inequality. The main areas of its manifestation are considered: by monetary income and wealth; current consumption of goods; access to housing and social infrastructure; as well as - in the spatial aspect; the standard of living and quality of life of urban and rural populations; sectoral aspect; age demographic groups; the use of digital technologies. Inequality was assessed and its high dimensions were reasoned, which is reflected in Russia's position in the group of countries with the

\footnotetext{
11 The research was carried out within the framework of the state task on the topic: "Components, social standards and indicators of the standard of living and quality of life of the population in contemporary Russia: qualitative identification and quantitative assessment in conditions of socio-economic inequality" (No. 0137-2019-0032).
} 
highest level of inequality in income and wealth; in a tenfold gap in average consumer spending among ten percent of the most and least income groups of households; in more than tenfold differentiation in the number of citizens with housing poverty and high housing security; in the inaccessibility for half of College and University students to study at the expense of budget allocations; the gap in life expectancy at birth in the regions of the Russian Federation with the highest and lowest values of the indicator is 16 years. There is three to five times higher unemployment among young people compared to other groups of the economically active population, etc. The question is raised about the need to develop a national program to increase the real monetary income of the population, reduce poverty and inequality.

Keywords: economic inequality, social inequality, high inequality, poverty, real monetary income, program to reduce poverty and inequality.

JEL Classification: E21, E24, E64, I3, J21.

DOI: $10.31737 / 2221-2264-2020-47-3-8$

\author{
Б.Е. Фрумкин
}

ИЭ РАН, ИМЭМО им. Е.М. Примакова, РАН, Москва

Аннотация. На основе теории опекаемых благ рассматривается развитие государственного опекунства в области обеспечения продовольственной безопасности населения с учетом ее корреляции с размером и дифференциацией доходов. Анализируются принципы и механизмы внутренней национальной (на примере США) и наднациональной (на примере Евросоюза) государственной продовольственной помощи малоимущим и другим уязвимым категориям населения в развитых экономиках. Особое внимание обращено на организационно-финансовый и социально-перераспределительный аспекты помощи, обеспечение ее адресного характера и привязки к уровню доходов, сочетание денежной и натуральной форм предоставления помощи, сопряжение продовольственной помощи с государственной поддержкой сельского хозяйства, роли НГО/НКО в системах государственной продовольственной помощи. Обоснована необходимость продовольственной помощи как важного элемента государственного опекунства в современной рыночной экономике, частично компенсирующего доходно-социальное неравенство, минимизирущего социальную депривацию. Показано принципиальное отличие такой помощи от карточной системы, связанной с недостаточным предложением и балансирующей его со спросом неэкономическими методами. Рассмотрено формирование национальной системы продовольственной помощи в России, предложены пути ее развития с учетом обновленной Доктрины продовольственной безопасности РФ и последствий коронакризиса.

Ключевые слова: опекаемые блага, экономическая доступность продовольствия, дифференииация доходов, продовольственная помощъ, пандемия коронавируса.

Классификация JEL: D6, H4, I3, Q18.

DOI: $10.31737 / 2221-2264-2020-47-3-9$

Развитие теории опекаемых благ позволяет усовершенствовать подходы к оценкам интересов и поведения индивидуумов, их групп и корректирующего их государства в обеспечении потребления таких благ. Ключевыми в этом смысле являются трактовки: опекаемых благ как товаров и услуг, «потребление которых государство в соответствии со своими предпочтениями стремится повысить или снизить»; нормативного интереса и соииальной полезности как основ активности государства в хозяйственной жизни общества; возникновение патерналистской активности государства там и тогда, где и когда согласно его установкам «оказывается неэффективной институциональная среда и/или признается неприемлемым распределение богатства; и /или поведение индивидуумов оценивается нераци- 